\title{
Application of Cigeratte Filter from Algae Spirogyra peipingensis to Reduce Nicotine, Tar, and Carbon Monoxide
}

\author{
Syamsul Bahri ${ }^{1}$, Kamsinar $^{1}$, Sarioja $^{1}$, Edi Tompo ${ }^{2}$, and Nurul Fahmiah ${ }^{1}$ \\ ${ }^{1}$ Department of Biology, Faculty of Mathematics and Natural Sciences, Hasanuddin \\ University, Makassar, Indonesia \\ ${ }^{2}$ Department of Animal Sciences, Faculty of Animal Sciences, Hasanuddin University, \\ Makassar, Indonesia
}

\begin{abstract}
Algae Spirogyra peipingensis is a group of green algae from the order Zygnematales. Spirogyra algae serves as a bioremediation agent. In addition Spirogyra algae has great potential in reducing toxin levels in cigarette smoke. Because the biomass of alga Spirogyra has an irregular shaped surface texture and consists of amino acid, amide, carboxylic, hydroxyl, and carbonyl group that can bind various heavy metals and other harmful compounds. Alga Spirogyra peipingensis samples used are algae from Bone, South Sulawesi. Prior to the trial, the first pretreatment and processed to become powder. Algae powder was then applied to cigarette filters and tested on several respondents. Results showed that there was a significant decrease tar, nicotine and carbon monoxide levels in cigarette smoke by using Spirogyra peipingensis algae but the most significant decrease of carbon monoxide, while tar and nicotine decreased even though not as high as carbon monoxide.
\end{abstract}

\section{Article History}

Received 8 May 2017

Accepted 3 July 2017

\section{Keyword}

Cigarette filters,

Spirogyra peipingensis,

Nicotine,

Algae.

\section{Introduction}

Smoking has been known to cause health problems (Ching, 2017; Chen, 2010). This health disorder can be caused by nicotine derived from mainstream smoke and secondhand smoke from smokers smoked cigarettes (Chen, 2017). Thus the sufferer is not only the smokers themselves (active smokers) but also people who are in the environment of tobacco smoke (Environmental Tobacco Smoke) or called passive smokers (Zenzhes, 2009; Castilla, 2005). Health disorders can include chronic bronchitis, emphysema, lung cancer, larvae, mouth, pharynx, esophagus, bladder, artery narrowing and others (Abedi, 2017; Bae, 2015). However, there are still many men and women who have not or can not leave this habit. Various efforts have been made by those concerned about environmental health from cigarette smoke, such as smoking bans in public places, special installations, and others (Huang, 2016). Even government warnings on tobacco packaging stating that smoking can harm health do not get a good response from the community (Huang, 2016; Tang, 2016). 
According to the World Health Organization (WHO), the environment of cigarette smoke is the cause of various diseases, and can also affect healthy people who are not smokers. Continuous exposure to secondhand smoke in healthy adults can increase the risk of lung disease and heart disease by 20-30 percent (Abedi, 2017; Atar, 2017; Bae, 2015). The environment of cigarette smoke can worsen the condition of a person with asthma, causing bronchitis, and pneumonia (Su, 2016; Stirk, 2015). Cigarette smoke also causes eye irritation and nasal passages for people around them (Wegrezensky, 2017; Wang, 2016). Cigarettes contain about 4,000 types of chemicals, of which 40 are carcinogenic, and at least 200 of them are hazardous to health. The main toxins in cigarette are tar, nicotine and carbon monoxide (Wang, 2016; Simsek, 2016). In addition, in a cigarette also contains other chemicals that are not less toxic that affect the health of the body (Damron, 2017).

Risks that can be caused by smoking can actually be reduced if known toxins levels in cigarette smoke such as nicotine, tar, and carbon monoxide. When these levels are listed then the candidate smokers can choose cigarettes with the content of toxins as small as possible or the least content of the types of cigarette. To overcome this problem, it is necessary to make a new innovation of cigarette filter made from algae Spirogyra peipingensis that effectively reduces toxins levels in cigarette smoke such as reducing the content are nicotine, tar, and carbon monoxide produced by cigarette smoke.

\section{Materials and Methods}

\section{Pretreatment}

The biomass of Spirogyra peipingensis was dried using oven at $80^{\circ} \mathrm{C}$ for 48 hours. The biomass of Spirogyra peipingensis blended until crushed and sieved with a mesh size of 40 mesh. Spirogyra algae biomass that passes 40 mesh sieve is weighed as much as 100 grams (Sulfahri et al., 2017; Zhang \& Feng, 2010). Spirogyra algae is then used as raw material of cigarette filter in accordance with the research design.

\section{Cigarette Filter Creation}

Cigarette filters of 0.7 in diameter and $5 \mathrm{~cm}$ in length are printed using a 3D printer with a design such as in Figure 1. Spirogyra powder-shaped algae is then inserted into a cigarette filter with an algae thickness of $2 \mathrm{~cm}$. The algae powder that has been inside the tube is then pressed with an iron ballast to condense Spirogyra algae powder. At each end of the cigarette filter is covered with a wool cloth with a diameter of wool cloth on each end with a length of $3 \mathrm{~mm}$.

\section{Cigarette Filter App}

Various types of cigarettes were applied to this cigarette filter to see the effect of the application using the Spirogyra peipigensis algae filter. The main toxin levels found in cigarettes are nicotine, tar and carbon monoxide which will be filtered by using Spirogyra peipingensis algae filter on $2 \mathrm{~cm}$ thickness and cigarette without using algae filter then measured nicotine, tar and carbon monoxide levels.

\section{Nicotine and Tar Levels Analysis}

Measurement of nicotine and tar content on clove and filter cigarettes refers to the Decree of the Indonesian Minister of Industry and Trade No. 62/MPP/Kep/2/2004 dated February 17, 2004 on How to Test Nicotine and Tar Content Levels for Kretek and Filters. Making a solution extract, weigh $1 \mathrm{~g}$ Chinaldine add $10 \mathrm{ml}$ of ethanol and then apply it with 
2-propanol in 2 liter flask. Making a mother liquor weighs $0.5 \mathrm{gr}$ of nicotine, $2.5 \mathrm{gr}$ of eugenol and $1 \mathrm{~g}$ of water then appropriately with the extracting solution in a $50 \mathrm{ml}$ flask. Make standard solution for calibration curve pipette of mother liquor as much as $1 \mathrm{ml}, 2 \mathrm{ml}, 3 \mathrm{ml}, 4$ $\mathrm{ml}, 5 \mathrm{ml}$ and insert in measuring flask $10 \mathrm{mh}$ Then apply until mark line with extract solution. Inject $2 \mathrm{ml}$ of the solution in $\mathrm{GC}$ to obtain the calibration curve. Extraction filter pad from smoking machine in $50 \mathrm{ml}$ extract solution, shake with shaker for 30 minutes with speed 270 rpm. Enter the extract in the vial, close the meeting. Insert $2 \mathrm{ml}$ of the solution, then test in Choromotoghrafi (GC) Gas to obtain nicotine and tar levels (ISO 3402-1999 \& ISO 10362-11999).

\section{Analysis of Carbon Monoxide (CO)}

To measure the concentration of $\mathrm{CO}$ in the air is used Drager Multigas Detector tool and the results can be read on a scale of reading between $100-3000$ ppm for 10 times the pressure, and between $100-3000$ ppm for 1 time pressure. The tool is a tube with a length of approximately $10 \mathrm{~cm}$, on the left on the wall there are scales of 100,500,1000, 2000, and 3000 which states the concentration of $\mathrm{CO}$ in ppm, while on the right on the wall there is a scale from 10 to 300 . Top is broken and connected with a pressure pump, if this tool will be used to measure CO concentration. By pressing the pump once can be measured air concentration between 100 to 300 ppm, while to measure the concentration of 10 to 300 ppm, the pump is pressed 10 times.

\section{Tool Saturation Test}

The cigarette smoke filter will be tested from 0 to 10 cigarettes and so on, then 20, 30,40 , and 50 cigarettes, the cigarette filter will be measured every 10 cigarette intervals with the measurement of nicotine, tar, And Carbon Monoxide (CO). If the levels are Nicotine, Tar, and Carbon Monoxide (CO) content less than $60 \%$ and then the tool filter used is already saturated threshold. If the cigarette filter tool is saturated then cigarette filter should be replaced new.

\section{Results and discussion}

\section{Algae Preparation}

Algae taken are Spirogyra peipingensis species in the rice fields by using a sieve then collected in the bag and then washed thoroughly. Subsequently algae were identified using a microscope and algae identification book. Set it algae dried in the sun to dry and blend until smooth. Algae that have been blended using $\mathbf{4 0}$ mesh sieve to produce algae flour which will using as raw material in making filter cigarettes.

\section{Cigarette Filter Creation}

Collecting waste wood from craftsman remain and other woods and then cut into pieces with a length of 100-132 mm, after that drill the middle of the wood with a diameter $7,60-8,00 \mathrm{~mm}$ as a place to discharge smoke then smoothing the surface of the wood with sandpaper and shaped like a picture that has been designed. Spirogyra already in powder pretreatment then put on cigarette filter with thickness of alga that is $2 \mathrm{~cm}$ by using horn spoon. The algae powder that has been inside the tube is then inserted and compacted. At each end of the cigarettes filter is covered with a wool cloth with a diameter of wool cloth on each end with a length of $3 \mathrm{~mm}$. 


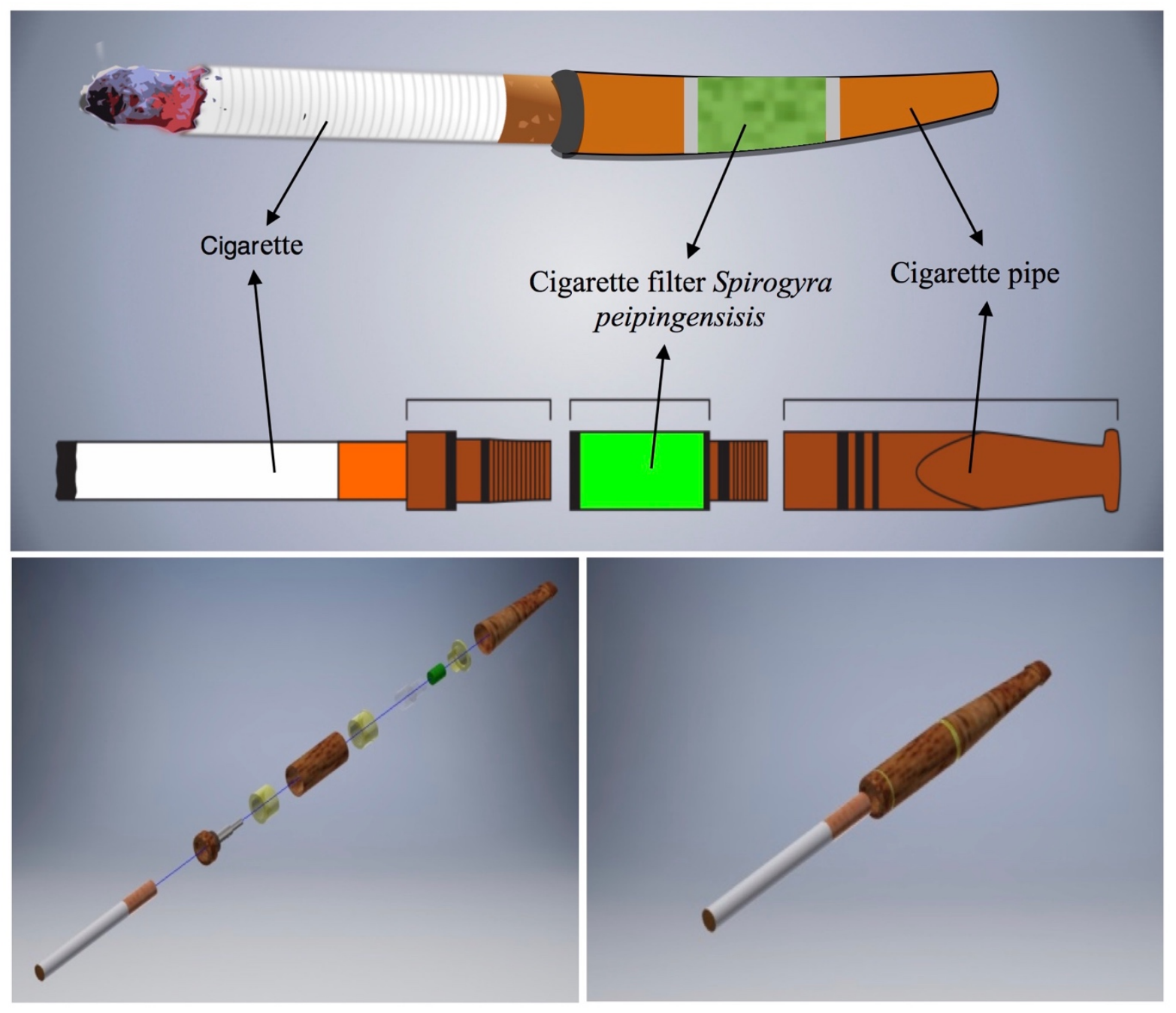

Figure 1. Cigerette Filter Desain

\section{Product Trial Results}

Cigarette filter products that have been made then tested it's ability in reducing toxin levels in cigarette smoke. The results show that, there is a significant decrease between cigarette smoke before it is filtered and after filter (Figure 3). Each content of Nicotine 30.8 ppm, Tar $20.5 \mathrm{ppm}$, and carbon monoxide $17.6 \mathrm{ppm}$. While the content of cigarette smoke that has been filter respectively that is $11.9 \mathrm{ppm}$ nicotine, $10.6 \mathrm{ppm}$ tar, and carbon monoxide $2.4 \mathrm{ppm}$. This is due to the content contained in algae that can absorb various compounds produced by cigarette smoke.

This is in accordance with opinion (Sulfahri et al., 2017) which states that the biomass of alga Spirogyra has an irregular-shaped surface texture consisting of amino acid, amide, carboxylic, hydroxyl, and carbonyl group capable of binding various heavy metals. It is also in line with opinion (Ozer et al., 2006) that Spirogyra algae can reduce blue textile dyes (Acid Blue 290 and Acid Blue 324). The process of remediation of Acid Blue 290 and Acid Blue 324 textile dyes is done by using the dead Spirogyra algae. The adsorption process using Spirogyra algae has the same way of working with activated carbon in absorbing various compounds in a solution. Dry Spirogyra algae can be utilized for water treatment (Gupta et al., 2006). 
Wastewater treatment, for surface water biomonitoring and as heavy commercial heavy metal waste adsorbents for application. Spirogyra algae can adsorb $\mathrm{Cu}$ and $\mathrm{Pb}$ in low or high concentrations. Capacity of heavy metal absorption by Alga Spirogyra are: $\mathrm{Cr} 14.7 \mathrm{mg} / \mathrm{g}$ d.m. (Gupta et al., 2001), Pb 140 mg / g d.m. (Gupta et al., 2008), Cu 133.3 mg / g d.m. Heavy metal ions which are absorbed by the dried algae of Spirogyra algae are $\mathrm{Mn} 2+, \mathrm{Cu} 2+, \mathrm{Zn} 2+$, and $\mathrm{Cd} 2+$, using the adsorbent capable of absorbing 90-95\% metal ions (Gupta et al., 2006).
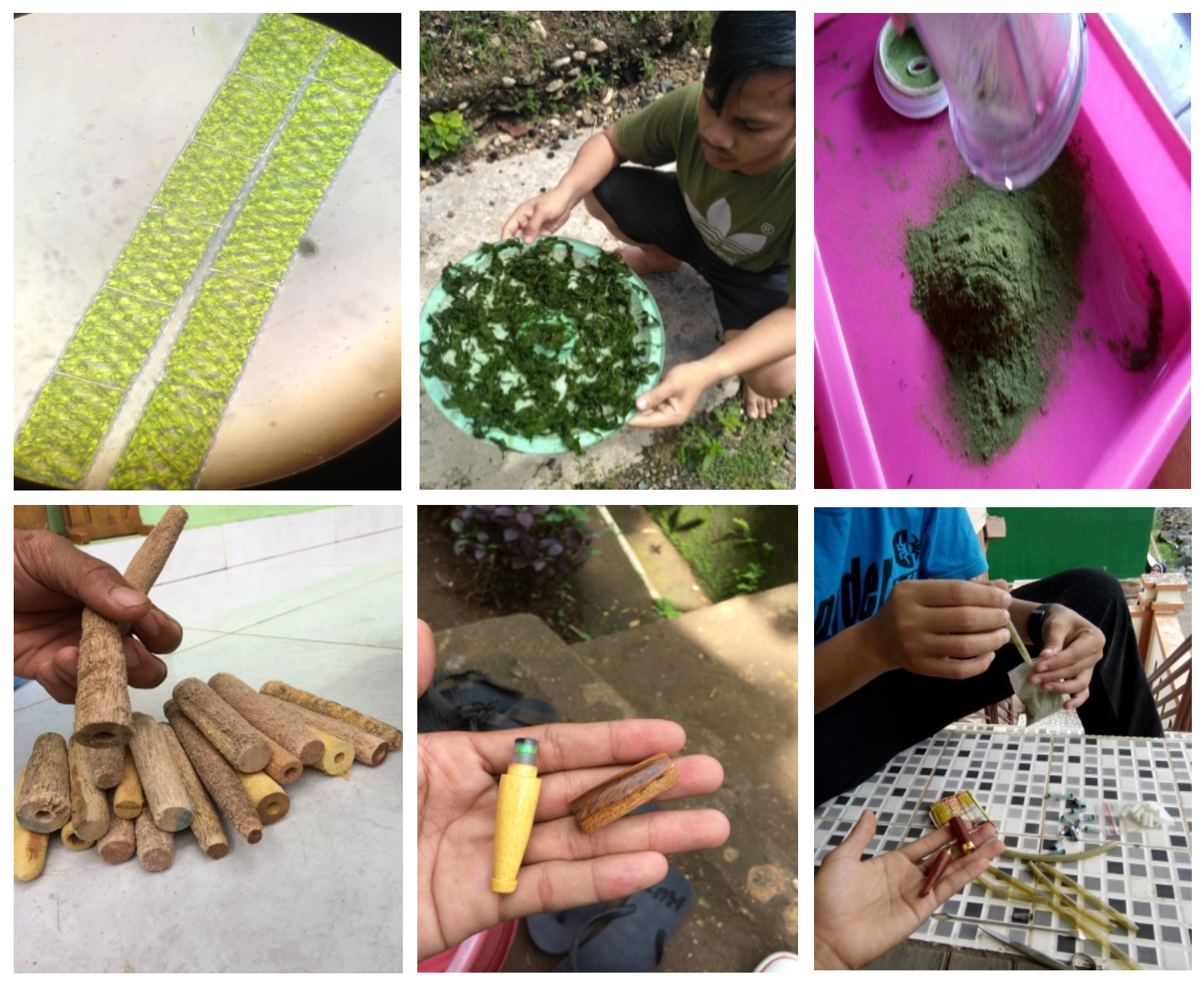

Figure 2. Cigarette filter assemble

\section{Test results of saturation tool}

Cigarette smoke filters will be tested for saturation point from 0 to 5 cigarettes sticks and so on. On the use of filters on 5 cigarettes was declared already saturated because the algae inside the filter has changed the color of the green color into a thick black color and the smell of algae also smells a bit stinging. Then the filter tool used was already saturated threshold. If the cigarette filter tool is saturated then cigarette filter should be replaced new. 


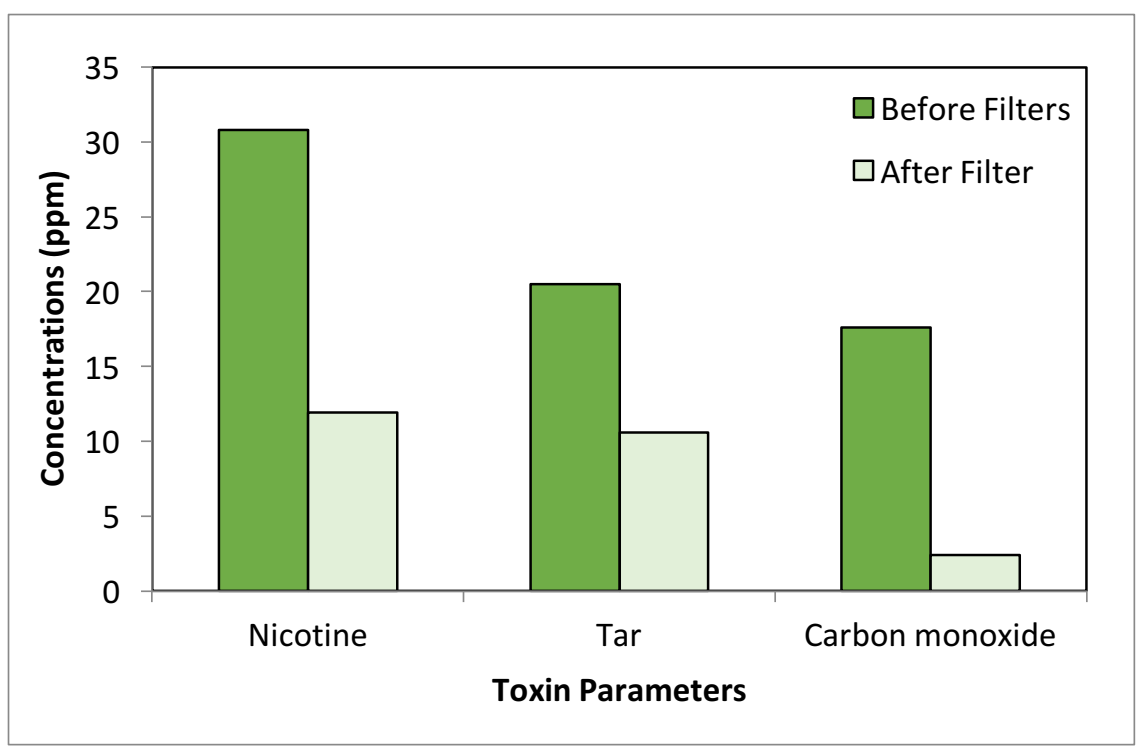

Figure 3. Graph of Laborotorium Analysis Result of Nicotine content, Tar, and carbon monoxide of cigarette smoke

\section{Organoleptic Test Results}

The organoleptic test was performed by hedonic method on 10 panelists. The test parameters included flavor and aroma. To the attachment presented cigarettes and filter samples of algae cigarettes then the panelists tried to suck it and then fill out the questionnaire based on the preferred levels according to the rating scale. Based on the results of organoleptic tests that have been done to 10 panelists obtained an average of 4.3 / 5.0 is a comparison of numbers with a very small difference, ie 0.1 means the potential of this cigarettes filter to be applied to the public. In addition to reducing levels of toxins such as nicotine, tar, and carbon monoxide, Spirogyra peipingensis algae-based filter is also in great demand by the public. So by applying this product is expected to reduce the various diseases of society caused by cigarettes.

\section{Conclusions}

Spirogyra peipingensis algae cigarette filter can reduce the content of nicotine, tar, and carbon monoxide in cigarette smoke significantly. Spirogyra peipingensis algae cigarette filter can reduce the content of nicotine by $61.36 \%$, tar by $48.29 \%$ and CO by $86,36 \%$. The decreasing content of toxins in cigarette smoke caused by the content contained in algae that can absorb various compounds produced by cigarette smoke.

\section{Acknowledgment}

The authors gratefully acknowledge financial support from the Ministry of Research, Technology and Higher Education of Indonesia with project PKM (Program Kreativitas mahasiswa) contract number 547/B3.1/KM/2017.

\section{References}

Abedi, M. 2017. Germination patterns of the scrublands in response to smoke: The role of functional groups and the effect of smoke treatment method. South African Journal of Botani. 111: 1-6 
Amstrong, B. K. 1984. Smoke and Health. BPOM. Jakarta [In Indonesian]

Atar, Y. 2017. Effects of Smoke Generated by Electrocautery on the Larynx. Journal of Voice. 31:380-388.

Bae, S. 2015. Development of a smoke effect model for representing the psychological pressure from the smoke. Safety Science. 77 : 56-65.

Cahyono, 1998. Tobacco, Cultivation And Analysis Of Farming, Kanisius. Yogyakarta. [In Indonesian]

Castilla, C. B. 2005. Ovotoxicity of cigarette smoke: a systematic review of the literature. Reproductive Toxicology. 74(1):479-489.

Chen, J. 2010. Protective effects of valsartan against cigarette smoke-induced left ventricular systolic dysfunction in rats. International Journal of Cardiology. 167:677-680.

Chen, J. 2017. Developmental cigarette smoke exposure II: Hippocampus proteome and metabolome profiles in adult offspring. Reproductive Toxicology. 65:436-477.

Ching, L. H., 2017. Physical activity, smoking, and the incidence of clinically diagnosed insomnia. Sleep Medicine. 30:189-194.

Damron, K. R., 2017. Review of the Relationships Among Psychosocial Stress, Secondhand Smoke, and Perinatal Smoking. Journal of Obstetric, Gynecologic, \& Neonatal Nursing. 46:325-333.

David E. 2003. Mayo Clinic Family Health Book. The ultimate home medical reference 3rd. USA: Mayo Clinic.

Feng, Z. 2010. Effects of ambient wind on thermal smoke exhaust from a shaft in tunnels with natural ventilation. Applied Termal Engineering. 117: 254-262.

Gupta, V.K., \& Rostogi, A. 2008. Biosorption of Lead from Aqueous Solutions by Green Algae Spirogyra Species: Kinetics and Equilibriumstudies. Journal of Hazardous Materrials. 152 : 407-414.

Gupta, V.K., Rastogi, A., Saini, V.K. \& Jain, N. 2006. Biosorption of Copper(II) from Aqueous Solutions by Spirogyra Species. Journal of Colloid Interface Science. 296 : 59-63.

Huang, J. L. 2016. Effect of Smoke Barrier in Narrow Space on Smoke Flow Utilizing CFD. Procedia Engineering. 135:142-150.

Ozer S, Yilmaz EI, Bayrak S, Tunc ES. 2012. Parental knowledge and attitudes regarding the emergency treatment of avulsed permanent teeth. European Journal of Dentistry. 6: 370375.

Simsek, C. 2016. Feelings of being disabled as a prognostic factor for mortality in the drug eluting stent era. Journal of Psychosmetic Research. 67:85-91.

Stirk, W. A. 2016. Effect of smoke-derived extracts on Spirodela polyrhiza, an aquatic plant grown in nutrient-rich and -depleted conditions. Aquatic Botany. Vol 129 (31-34).

Sulfahri, Amin, M., Soemitro, S.B. \& Saptasari, M. 2017. Comparison of Biomass Production from Algae Spirogyra hyalina and Spirogyra peipingensis. Biofuels. 8(3):359-366.

Su, H. C., 2016. Performance measurement of a smoke extraction system for buildings in fullscale hot smoke test. Measurement. 93:340-350.

Tang, P. 2016. A Biology of The Algae, 3rd edition. Georgetown University, United States of America.

Wang, F. 2016. Numerical study on fire smoke movement and control in curved road tunnels. Tunnelling and Underground Space Technology. 67:1-7.

Zarina, A., Hasana, M.U. \& Shameel, M. 2007. Diversity of the Genus Spirogyra (Zygnemophyceae Shameel) in the North-Eastern Areas of Pakistan. Proceedings of The Pakistan Academy of Sciences. 44 (4) : 225 - 248. 
Zenzhes, Y. J. 2009. Effect of moxa smoke produced during combustion of Aiye (Folium artemisiae Argyi) on behavioral changes in mice inhaling the smoke. Journal of Traditional Chinese Medecine. 36:80-811.

Zhang, K. \& Feng,H. 2010. Fermentation Potentials of Zymomonas mobilis and its Application in Ethanol Production from Low-cost Raw Sweet Potato. African Journal of Biotechnology. $9(37): 6122-6128$.

\section{To cite this article:}

Bahri, S., Kamsinar, Sarioja, Tompo, E. \& Fahmiah, N. 2017. Application of Cigeratte Filter from Algae Spirogyra peipingensis to Reduce Nicotine, Tar, and Carbon Monoxide. International Journal of Applied Biology. 1(1):1-8. 